\title{
Pluralismo político y rol del moderador en tertulias televisivas: Al Rojo Vivo y Las Mañanas de Cuatro
}

Noel Bandera López | noelbandera@hotmail.com Universidad de Valencia

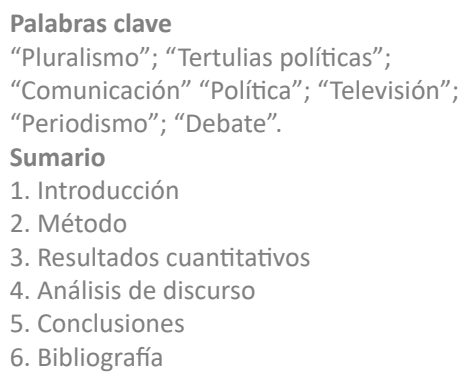

\section{Resumen}

Las tertulias televisivas poseen gran relevancia en el nuevo ciclo político abierto en España en 2014. Con vistas a analizar el grado de pluralismo político y el rol del moderador que se despliega en ellas, se ha tomado una muestra de 50 programas (25 de "Al Rojo Vivo" y 25 de "Las Mañanas de Cuatro"). La perspectiva es cualitativa respecto al alcance del marco permitido y cuantitativa en cuanto al tratamiento que reciben los partidos políticos. Las número de intervenciones que realiza un partido por cada contraargumento que recibe de los periodistas. Del análisis se extraen conclusiones sobre las deficitarias condiciones en las que se despliega un pluralismo muy sesgado por la orientación política de los programas, y un trato radicalmente distinto dependiendo de cuál sea el partido entrevistado. Las limitaciones son las propias de una metodología empleada por vez primera y el hallazgo principal sería el alineamiento de ambos programas en el enfoque general y en el tratamiento a los diversos partidos.

\section{Cómo citar este texto:}

Noel Bandera López (2019): Pluralismo político y rol del moderador en tertulias televisivas: Al Rojo Vivo y Las Mañanas de Cuatro, en Miguel Hernández Communication Journal, n¹0 (1), pp. 39 a 56. Universidad Miguel Hernández, UMH (Elche-Alicante). DOI: http://dx.doi.org/10.21134/mhcj.v10i0.265 


\section{Political pluralism and role of the moderator in television gatherings: Al Rojo Vivo and Las Mañanas de Cuatro}

Noel Bandera López |noelbandera@hotmail.com

Universidad de Valencia

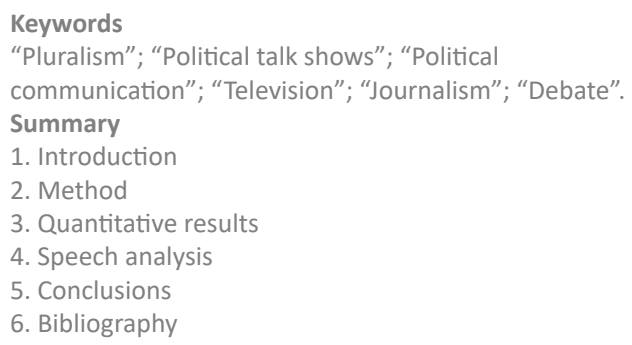

\section{Abstract}

Political talk shows have been very relevant under the current new cycle initiated in Spain in 2014. To analyse the degree of political pluralism and the role of the host developed in them, it has been taken a sample of 50 programmes (25 for "Al Rojo Vivo" and 25 for "Las Mañanas de Cuatro"). The approach is qualitative in relation to the reach of the tolerated views and quantitative in order to know the treatment received by different political parties. Registered variables are about who, how much and how intervenes in each programme. It is obtained the number of interventions by each political party in comparison with the counterreasons expressed by journalists. Conclusions are extracted on the limited conditions in which pluralism happens and radical differences depending on who is the interviewed party. Main constraints for the investigation are the ones expected for a new untested method and an important finding would be the alignment of both TV shows under the same general perspective and treatment of concerned political parties.

\section{How to cite this text:}

Noel Bandera López (2019): Political pluralism and role of the moderator in television gatherings: Al Rojo Vivo and Las Mañanas de Cuatro, in Miguel Hernández Communication Journal, n¹0 (1), pp. 39 a 56. Universidad Miguel Hernández, UMH (Elche-Alicante). DOI: http://dx.doi.org/10.21134/mhcj.v10i0.265 


\section{Introducción, objetivos y metodología}

Desde el inicio del nuevo ciclo político en España en 2014, las tertulias políticas televisivas han sido un escenario clave en el día a día político; muestran su relevancia sus altos índices de audiencia y la frecuente aparición en ellas de representantes políticos e incluso de líderes de partidos. La academia había estudiado el formato ya en años anteriores (por ejemplo, vinculando su desarrollo a la hibridación con formatos de reality show y crónica rosa -Palao Errando y García Catalán, 2011-).

La investigación que se introduce tiene como propósito nuclear recabar información sobre las condiciones en que se desarrollan las tertulias políticas televisivas en España, el pluralismo que se despliega en ellas y en concreto cuánto y cómo pueden intervenir los distintos representantes partidistas en dos tertulias seleccionadas (Al Rojo Vivo y Las Mañanas de Cuatro).

Aunque conviva con muchos otros (y algunos en permanente crecimiento), la televisión continúa siendo en pleno siglo XXI el instrumento principal para la información política, como atestiguan los estudios postelectorales del Centro de Investigaciones Sociológicas. Un motivo central de interés al elegir La Sexta y Cuatro para los efectos de este artículo es que se trata de las dos cadenas que se ubican más a la izquierda entre las televisiones generalistas (en la percepción generalizada y en la Encuesta GIPEyOP/Mediaflows sobre Medios y Comunicadores, con 5414 respuestas válidas y trabajo de campo hasta el 04/01/2017 $)$, lo cual puede proporcionar indicios relevantes sobre el grado de aperturismo del actual sistema mediático español. Los encuestados situaron a La Sexta en un 2.9 y a Cuatro en el 4.1, siendo 0 la izquierda y 10 la derecha. El conductor de uno de los dos programas aquí analizados, Antonio García Ferreras (Al Rojo Vivo), fue ubicado en la encuesta con un 2.8.

Además, que los dos programas analizados correspondan a los dos grandes grupos mediáticos dará un significado añadido a la conclusiones del estudio en sí, pues conoceremos mejor la amplitud del espectro de opiniones permitido a finales de 2017 en la televisión española. En la muy usada distinción entre pluralismo externo y pluralismo interno, esta derivada correspondería al primer tipo, mientras que el objeto central del artículo es, en cualquier caso, el pluralismo interno desarrollado en dos programas.

Respecto a la posible generalización de los resultados, y si bien algunas tendencias políticas son inequívocas y relativamente permanentes, es oportuno señalar, como demuestran Sánchez Castillo, Peris Blanes \& Fenoll (2016), que los medios de comunicación, y en concreto los tradicionales, pueden variar su aproximación a determinadas cuestiones o partidos en breve espacio de tiempo. Los resultados del trabajo de estos autores contraponen la continuidad en el discurso de cuatro medios digitales con los cambios sustanciales que se registran después de las elecciones europeas de 2014 en cuatro cabeceras de la prensa escrita.

El principal objetivo de la indagación será actualizar, al menos parcialmente, el conocimiento sobre el estado del pluralismo político en el espacio televisivo español, en particular las tertulias, y sobre el alto grado de paralelismo político que caracteriza a los medios españoles, como resumen Campos Domínguez, López García \& Valera Ordaz (2013: 37):

Esta inclinación hacia el periodismo opinativo, combinada con el ya mencionado "activismo político" ejercido por las empresas mediáticas, lo que algunos han bautizado como periodismo sacerdotal (Mazzoleni, 2011), proporciona evidencia empírica de un

\footnotetext{
${ }^{1}$ https://www.uv.es/pavia/Informe Encuesta Medios.pdf
} 
alto grado de paralelismo político (Hallin y Mancini, 2008), es decir, la existencia de fuertes y profundos vínculos entre los actores políticos y los medios.

Aunque los expertos suelen presentarse como analistas técnicos, alejados de la mundanal política y con un halo de neutralidad, en Las Mañanas de Cuatro puede oírse por ejemplo al economista Gay de Liébana insistiendo en que la economía empeorará gravemente si no se vota a los "partidos constitucionalistas" o al politólogo Nacho Corredor argumentando que solo el candidato del PSC puede reunir suficientes apoyos y abstenciones.

A estos posicionamientos partidistas explícitos se deben añadir los implícitos, más numerosos e interesantes, y que se vertebran con el framing y la agenda setting. El director de orquesta que aúna todos los instrumentos para la construcción mediática de la realidad es el moderador, cuyas intervenciones son por tanto esenciales para los objetivos de este trabajo, que se diferencia en este punto de otros como el de Santamaria Guinot: "Como el papel del conductor del programa es dirigir la tertulia hacia los temas que se quieren debatir en público no analizaremos las intervenciones ni de Xavier Coral ni de Helena Garcia Melero” (2017: 132).

La aproximación desarrollada considera al conductor, en cambio, como un actor "convertido en icono de la propia cadena, que tanto al moderar como al explicitar su punto de vista define el temario, pero también el tono, el perfil dramático y el encuadre desde el que se abordan los temas. Los contertulios siguen esas pautas [...]” (León Gross y Gómez Calderón, 2011: 68).

Como se desprende de estudios como el de Carniel Bugs y Sabés Turmo (2014) o Botella (2006), la ausencia de organismo regulador del audiovisual en el contexto español (además de ser algo inédito en la UE -Cotarelo, R. y Gil J. (2017), nota 149-) dificulta el cumplimiento de los principios de pluralismo. En la misma línea apuntaba Miguel de Bustos (2004: 15): hoy más que nunca es clave "establecer políticas de regulación del pluralismo, porque resulta fundamental asegurar que el diseño de las nuevas redes y de sus capacidades no se haga exclusivamente a partir de objetivos comerciales, que podrían implicar una exclusión de los grupos menos favorecidos".

Aunque hay órganos autonómicos que sí tienen encomendadas algunas funciones al respecto (Catalunya y Andalucía), el vacío a nivel estatal hace que proyectos como el que aquí se introduce cobren mayor importancia para conocer el grado de pluralismo desplegado en programas relevantes del medio de comunicación más popular. La posición histórica de la Comisión Europea tampoco ha ayudado en este sentido, pues "la única alusión clara a la trascendencia democrático-informativa de las actividades de los medios de comunicación queda relegada al sector prensa" -Rodríguez Pardo (2005: 125), analizando el papel de la Comisión en las concentraciones mediáticas- y "esta postura, en cambio, no es trasladada al ámbito del sector televisivo cuya labor informativa es, sin duda, menor, pero de mucha mayor influencia”.

Se pondrán a prueba tres hipótesis:

A) En consonancia con la clásica adscripción de España a sistemas mediáticos mediterráneos, polarizados y con alto paralelismo político (Hallin y Mancini, 2004), encontraremos diferencias significativas en el trato dado a los partidos según su ideología, aun cuando los partidos políticos se presentan de forma proporcional a su poder parlamentario (Hallin y Mancini, 2004: 31).

B) Habiendo justificado la ubicación de Cuatro y La Sexta como las cadenas generalistas más a la izquierda, quienes reciban un mayor número de contraargumentos en las entrevistas serán 
los representantes del partido en el Gobierno, el Partido Popular, dado que es ubicado como el más conservador en las encuestas del Centro de Investigaciones Sociológicas y representa además la mayor posición de poder institucional en el periodo examinado.

C) Habiendo justificado la ubicación de Cuatro y La Sexta como las cadenas generalistas más a la izquierda, serán los partidos más a la izquierda quienes disfruten de un menor ratio de contraargumentos.

\section{Metodología}

Se han elegido dos programas representativos del género de la tertulia política en la televisión española actual. Los dos comparten horario (generalmente desde las 11.20 hasta las 14.15 horas, excepto en días especiales, que comienzan antes) y registran audiencias muy superiores a la media de sus respectivas cadenas: La Sexta para Al Rojo Vivo y Cuatro para Las Mañanas de Cuatro. De hecho, es habitual ver a Las Mañanas de Cuatro como el programa de mayor share de su cadena, mientras que Al Rojo Vivo se ha instalado en esa posición con asiduidad e incluso batió sus récords de audiencia en el período estudiado. Éste comprende los 25 programas emitidos a partir del 17 de octubre de 2017, excluyendo programas especiales en horario de tarde o noche. La única excepción es el programa de Las Mañanas de Cuatro del 17 de noviembre, que al no ofrecerse en la web de Cuatro ${ }^{2}$ se ha sustituido por el programa del 22 de noviembre (día inmediato posterior al último analizado).

El estudio de las 50 emisiones que componen la muestra se divide en dos grandes partes: una, de índole cualitativa, consiste en un análisis de contenido del pluralismo político desplegado, en sentido amplio, en estas tertulias, y sus principales hallazgos se exponen en el apartado 4.

En este examen de discurso se han seguido premisas que, como la que expone aquí Abril (2010: 35), intentan desvelar el contenido ideológico a partir tanto de lo aparente como de lo ocultado y lo secundario:

"Lo aparentemente secundario desde el punto de vista de la significación, es lo primario desde el punto de vista del sentido, y una parte fundamental de la vigencia y la eficacia de la ideología reside en hacer efectiva esa inversión del significado de lo aparente".

En cuanto a la otra parte del análisis, en el apartado 3, "Resultados", se presentan los datos derivados de una metodología para evaluar el tratamiento que se da en concreto a los partidos políticos que intervienen. Según este método, un "contraargumento" comprende toda intervención del moderador que implique una impugnación del argumento central del entrevistado o de la posición general de su partido. Se incluyen las intervenciones del moderador durante las entrevistas a representantes políticos, así como las intervenciones que él u otros tertulianos realicen inmediatamente después de la entrevista.

Ejemplos de refutación: "está usted diciendo exactamente lo contrario", "no me compare la situación catalana con la vasca", "el argumento del Ejecutivo es justo al contrario: ustedes son los que se han saltado la ley", "eso no es lo que dice su partido en Madrid", etc.

${ }^{2}$ Las dos fuentes utilizadas han sido por tanto las respectivas páginas web de los programas: https:// www.atresplayer.com/lasexta/programas/al-rojo-vivo/ y https://www.mitele.es/programas-tv/las-mananasde-cuatro/0000000020059/

Para realizar comprobaciones sobre los datos también se ha utilizado esta otra página donde pueden oírse los programas: https://www.ivoox.com/podcast-mananas-cuatro-mediaset sq f1135933 1.html 
A partir de esa unidad de medida, otros argumentos, reconvenciones o críticas del moderador que posean menor entidad se ponderan en consecuencia. Así, un "rebatimiento parcial" se contabiliza como media unidad y un rebatimiento de matiz como un tercio de la unidad. El rango que se asigna a las preguntas especialmente escépticas o críticas va desde 0,5 hasta 1,00 punto. Las repreguntas o insistencias no se consideran rebatimientos necesariamente.

Por supuesto, esta simple propuesta de ponderación esbozada es orientativa y la inclusión de una frase cualquiera en un tipo u otro podría debatirse, pero la cantidad total de contraargumentos es lo suficientemente amplia como para ser significativa, más allá de las limitaciones de cualquier codificación.

El número resultante de rebatimientos se ha contrastado con el número total de intervenciones de cada partido para obtener así los índices de refutación (o número de intervenciones que realiza cada partido por cada contraargumento recibido).

Se considera que la combinación del número de intervenciones y el número de rebatimientos dibuja una idea lo suficientemente precisa sobre las condiciones en que se expresan en estas tertulias los distintos partidos políticos, mientras que el enfoque cualitativo que analiza el contenido en el apartado 4 permitirá ahondar en el tratamiento que se da al pluralismo político en sentido amplio (no meramente partidista) y también en la parte de los programas que no es entrevista política.

Para seleccionar la muestra de programas a analizar se ha optado por un período no electoral, ya que, como indica López García (2004: 194)

la creación de un horizonte social de referencia por parte de los medios es obviamente un proceso largo, con lo que si nos situáramos estrictamente en esta perspectiva cognitiva parecería lógico situar en un segundo plano la importancia de las campañas electorales, pues el efecto de los medios sobre el público es continuado: los medios marcan continuamente al público quiénes son los candidatos con posibilidades, qué temas de campaña son importantes y cuáles no, qué errores y aciertos ha cometido cada agrupación política.

Sobre las limitaciones de la investigación, para afinar y desarrollarse, la nueva metodología (cuyos resultados se exponen en el apartado 3) precisa de más casos de estudio, así como de variables complementarias sobre el pluralismo político en estas tertulias televisivas -por ejemplo, el componente emocional es el centro en Santamaria Guinot (2017) o en Wirth y Schramm (2005)-.

La validez interna del trabajo cuantitativo se habría fortalecido con el trabajo de investigadores adicionales, con vistas a comparar sus ponderaciones de una muestra y obtener datos sobre la fiabilidad de la codificación presentada. 


\section{Resultados cuantitativos}

Tabla I. Intervenciones de partidos políticos en entrevistas de Las Mañanas de Cuatro

(17 octubre -22 noviembre 2017)

\begin{tabular}{|l|l|l|ll|}
\hline $\begin{array}{c}\text { Las Mañanas } \\
\text { de Cuatro } \\
\text { +Presencias en mesa } \\
\text { de debate político }\end{array}$ & $\begin{array}{c}\text { Intervenciones } \\
\text { +otras refutaciones } \\
\text { menores }\end{array}$ & $\begin{array}{c}\text { Intervenciones por cada } \\
\text { refutación recibida }\end{array}$ \\
\hline Compromís & $13+0$ & $0+0$ & - & \\
\hline PSOE-PSC & $93+5$ & $4+3,5$ & 12,4 & {$[+5$ debates $]$} \\
\hline Ciudadanos & $29+5$ & $3+1,33$ & 6,7 & {$[+5$ debates $]$} \\
\hline PP & $42+5$ & $6+1,83$ & 1,86 & {$[+5$ debates $]$} \\
\hline $\begin{array}{l}\text { Unidos Pode- } \\
\text { mos-ECP }\end{array}$ & $105+5$ & $45+11,58$ & 1,41 & [+3 debates $]$ \\
\hline PdeCat & $52+3$ & $28+8,75$ & 1,58 & \\
\hline ERC & $68+0$ & $38+5$ & 1,58 & \\
\hline CUP & $21+0$ & $12+1,33$ & & \\
\hline
\end{tabular}

*El ratio "intervenciones por cada refutación recibida" (columna 3) incluye también las refutaciones realizadas en las mesas de debate político que se celebraron en la primera hora de 5 de los programas de Las Mañanas de Cuatro. Los números entre corchetes corresponden a las presencias en esas mesas de debate, cuyas intervenciones no han sido subsumidas al calcular el ratio señalado.

Tabla II. Intervenciones de partidos políticos en entrevistas de Al Rojo Vivo (17 octubre -17 noviembre 2017 )

\begin{tabular}{|l|l|l|l|}
\hline $\begin{array}{c}\text { Al Rojo } \\
\text { Vivo }\end{array}$ & Intervenciones & $\begin{array}{c}\text { Contraargumentos }+ \\
\text { Otras refutaciones } \\
\text { menores }\end{array}$ & $\begin{array}{c}\text { Intervenciones por cada } \\
\text { refutación/contra- } \\
\text { argumento recibido }\end{array}$ \\
\hline PSOE-PSC & 205 & $3+2$ & 41 \\
\hline Ciudadanos & 90 & $3+3$ & 15 \\
\hline $\begin{array}{l}\text { Unidos Pode- } \\
\text { mos-ECP }\end{array}$ & 149 & $15+8$ & 6,48 \\
\hline Compromis & 4 & 1 & 4 \\
\hline PP & 72 & $8+10,09$ & 3,98 \\
\hline UPyD & 3 & 0 & - \\
\hline PdeCat & 113 & $37+8,33$ & 2,49 \\
\hline ERC & 64 & $25+5,5$ & 2,1 \\
\hline CUP & 26 & $13+2,25$ & 1,7 \\
\hline
\end{tabular}


Las Mañanas de Cuatro y Al Rojo Vivo presentan cuadros muy similares: en ambos casos, Ciudadanos y sobre todo el PSOE son los principales beneficiados en relación al número de contraargumentos que reciben, mientras que los tres partidos catalanes son los que salen peor parados. La graduación es prácticamente idéntica en las dos tertulias: en primer lugar, destacado, aparece el PSOE, con muy pocos contraargumentos sufridos; a cierta distancia, Ciudadanos; a continuación, el PP; y por último los tres grupos catalanes, muy parejos en el último nivel. Unidos Podemos recibe un tratamiento negativo cercano al de los grupos catalanes en Las Mañanas de Cuatro. En Al Rojo Vivo los representantes de este grupo parlamentario disfrutan un mejor tratamiento, pero siguen estando muy lejos de PSOE y Ciudadanos.

El número de intervenciones de cada partido constituye un dato valioso para conocer la visibilidad que disfruta cada opción política. Debe ser matizado, entre otros elementos, considerando que la posición del Gobierno es siempre oída de una manera u otra, especialmente a través de cortes de video. Además, el Partido Popular ha sido tradicionalmente partidario de tener un perfil bajo en este tipo de tertulias (sobre todo cuando se hable de corrupción), lo que explicaría su menor nivel de intervención en comparación con los otros partidos grandes.

Dentro de cada formación también pueden encontrarse algunos datos de interés. El más significativo se da con el PdeCat. En los otros 49 programas analizados, este partido no había tenido nunca una entrevista con más de 9 intervenciones. El 31 de octubre, sin embargo, Santi Vila no solo supera esas 9 y las duplica, sino que alcanza las 22 intervenciones. El tratamiento que recibe es radicalmente opuesto al de sus demás compañeros de partido: además del número de intervenciones, es recibido como invitado especial en el plató y los contraargumentos, prácticamente inexistentes, poseen una frecuencia muy lejana al índice que recibe el PdeCat excluyéndole a él: un contraargumento por cada dos intervenciones. El motivo de esta vastísima disparidad no es periodístico sino político: Santi Vila quiere ser el candidato de un PdeCat muy diferente al de los últimos años, que abandone el independentismo o al menos la vía unilateral.

\section{Análisis de discurso}

En los dos primeros subapartados se exponen las radicales divergencias entre la aproximación al IBEX-35 y la aproximación a la política no institucional que despliegan estas tertulias. En el tercero y cuarto se habla sobre el tratamiento que reciben las tesis que quedan fuera del marco aceptado. Por último, se analiza el estilo periodístico puesto en práctica.

\subsection{La sacralización de los mercados}

Aunque muy reducido en sus contornos, el debate sobre cuestiones partidistas o judiciales existe en estas tertulias políticas. El que no existe es el debate sobre el papel que debe jugar el poder económico y la compatibilidad del sistema capitalista con las dinámicas democráticas o con el sostenimiento del planeta. Primero, porque nunca se introducen debates relacionados con esta cuestión. Segundo, porque las visitas al parquet del IBEX 35 son solo para recabar información, cual oráculo que emite señales incontrovertibles. Es un templo sagrado y así son percibidos sus movimientos. Toda situación política indeseada por las grandes empresas es presentada en última instancia como un chantaje: se van las empresas, subirá el paro, se desestabilizaría la economía.

En el contexto de la completa subordinación de la democracia ante el capitalismo neoliberal, 
el periodista de los grandes medios de comunicación se limita a reproducir una y otra vez los deseos de los poderes económicos mediante la desproporcionada relevancia que concede a sus vaivenes, que casi nunca son cuestionados.

Un repunte del IBEX es presentado como agua bendita. Cuando Puigdemont parece que va a convocar elecciones, se insiste en que los mercados están festejando la solución. Pero no se produce el hecho que los mercados (y sus altavoces político-mediáticos) deseaban, por lo que ahora hay una amenaza de proclamar la republica mientras los mercados [están] sangrando. El día después, 27 de octubre, la palabra "sangrando" es pronunciada otras tres veces en relación al IBEX 35 y se remarca: absolutamente todos los mercados en verde excepto el de España.

El 30 de octubre, con el Govern cesado por Mariano Rajoy, Javier Ruiz no puede contener la emoción: Dios mío de mi vida cómo está la bolsa española... es un descorchar champán constante... disparados... estamos en mejores datos históricos, aunque luego es uno de los mejores días de los dos últimos años. Los mercados están descorchando champán, festejando..

Realiza una conexión con quien le confirma que el dinero siempre habla, Javier, y abora está diciendo que no habrá independencia de Catalunya. A lo que el presentador responde sugiriendo que es el principio del fin y que tanto los mercados como el Parlament han asumido que estamos ante la solución, en alusión a la aplicación del artículo 155. El ex-ministro García Margallo le corrige y afirma que no es el principio del fin, sino el fin, lo cual acepta.

En los grandes medios de comunicación y en concreto en la televisión son inexistentes o excepcionales las ocasiones en las que algún interviniente duda de que la satisfacción de los mercados sea un objetivo, una referencia o un indicador destacado. En esa línea, nadie plantea dudas sobre posibles incompatibilidades entre democracia y capitalismo o derechos humanos y capitalismo, unas dudas legítimas y que en cualquier caso deberían poder ser planteadas en el seno de cualquier sistema autodenominado democrático. En todo momento se presta atención a las tendencias de los mercados como oráculos intocables, con conexiones y actualizaciones prácticamente diarias. Solo en una ocasión la presentadora ocasional de Al Rojo Vivo Cristina Pardo pone en tela de juicio con una ironía la credibilidad de unos agentes económicos determinados (las agencias de rating). Pero la utilización del miedo respecto a las consecuencias en la economía catalana y española del Procés soberanista fue un recurso permanente en los dos programas.

\subsection{La democratización como peligro}

A diferencia del trato que recibe toda la información concerniente a los poderes económicos, la participación politica no institucional de los ciudadanos es presentada de manera despectiva e incluso criminalizadora, ya sea vía manifestaciones o huelgas, vía democracia interna o vía redes sociales (Twitter como espacio para más que un linchamiento-Ferreras, 6 de noviembre- o como botellón-Ferreras, 10 de noviembre-).

Arden las calles es, por ejemplo, una expresión muy utilizada en Las Mañanas de Cuatro, cuyo moderador llega a contraponer el concepto "política" y el concepto "calle". Del mismo modo que el tertuliano José María Brunet, periodista de La Vanguardia, quien, refiriéndose a las alusiones a Puigdemont como "traidor" por la posibilidad de que convoque elecciones, afirma que es el precio que hay que pagar por llevar la política a la calle, que nunca debió salir de las instituciones. Según este periodista el problema consistía en que se ha becho de la calle un agente político. 
Cuando Joan Tardá, diputado de ERC, apela a los catalanes que saldrán a la calle pacífica y cívicamente, Javier Ruiz (programa del 25 de octubre) insiste en considerar la frase de Tardá una amenaza, introduciendo la cuestión varias veces en la mesa de debate y luego dirigiéndola a sus entrevistados.

Más ejemplos en Las Mañanas de Cuatro: Se está calentando la calle, se está calentando la calle para el sábado, imágenes duras, durísimas, colapso total, los piquetes sembraron el pánico...

A Joan Josep Nuet (26 de octubre) se le pregunta itemen que la calle haya ido más allá de la política, que arda la calle?, muy similar a la pregunta a Xavier Albiol un día después. Ese mismo día se pregunta a Miquel Buch ¿va a haber violencia en la calle? El colaborador Juan Soto Ivars colabora en el framing del moderador: más metáfora violenta para encuadrar la participación de la sociedad. Para ellos la calle se refiere a poblaciones enfervorecidas. Gente que ha estado insultando a Puigdemont, al que ayer se encumbraba. Por eso culmina con esta frase: ayer Puigdemont sacó la cabeza a la calle y el aire que le vino fue directamente de guillotina. La siguiente pregunta del moderador, como no podía ser de otro modo: ¿cómo acaba esto, con problemas en la calle?

Aunque la democratización tanto de los partidos políticos internamente como en general respecto a las decisiones políticas sea un desiderátum bastante generalizado, en Las Mañanas de Cuatro y Al Rojo Vivo las consultas ciudadanas suelen provocar desdén.

Cuando Barcelona en Comú organiza una consulta interna para decidir si mantener al PSC como socio preferente, Javier Ruiz denuncia (13 de noviembre) que 2000 personas han decidido el destino de 1,6 millones. Pilar Gómez, subdirectora de La Razón, dice en Al Rojo Vivo (7 de noviembre) que se gasta mucho en participación en el Ayuntamiento de Madrid y luego votamos 2 personas.

Algunos partidos pusieron en duda la legitimidad de las elecciones catalanas del 21 de diciembre pero solo la CUP consultó a su militancia la decisión de participar en ellas. Este mérito en términos de democracia interna no era tal para la reportera Desiree Hernández (Las Mañanas de Cuatro), que subraya que la CUP aún no ha aclarado siquiera si se presenta pero no informa de que la decisión tiene fecha y se tomará democráticamente.

\subsection{La amplitud del marco}

En las televisiones españolas se dan enfrentamientos dialécticos, si bien estos tienen mucho de efectismo, poca argumentación y poca distancia ideológica real entre los participantes. Al Rojo Vivo es un buen ejemplo de ello, pues muchos de los debates se centran en matices. En cualquier caso, la amplitud del marco representado y permitido en Cuatro y La Sexta es similar al de otras televisiones, lo único que cambia es el partido privilegiado (PP normalmente, PSOE en las dos tertulias analizadas). Algo en línea con los rasgos mediáticos del modelo mediterráneo de medios de comunicación que plantearon Hallin y Mancini (2004) y su fuerte vinculación entre partidos y medios.

La posición minoritaria en las tertulias, que casi nunca es rupturista respecto al régimen actual sino meramente reformadora, tiene a todos los demás participantes en contra, incluyendo usualmente al propio moderador. Para subrayar la soledad o error de la argumentación minoritaria se recurre a múltiples instrumentos. Uno de ellos, utilizado por los demás tertulianos, es hablar en plural al periodista "minoritario", incluyéndolo como parte del 
independentismo ("vosotros, los indepes", "tu argumentario"...). Otro recurso, en este caso empleado por el moderador, es referirse al supuesto contenido "provocador" del entrevistado, con expresiones como "me has desatado a la mesa", "me has encendido a la mesa", etc.

El 14 de noviembre, el moderador de Las Mañanas de Cuatro presenta a los portavoces de PP, PSOE y Ciudadanos (Pablo Casado, Margarita Robles y Albert Rivera) como todos los partidos. Más tarde insiste y se refiere a esos tres partidos como todos los partidos de Madrid. La tarea de invisibilización de las posiciones alternativas sigue su curso, construyendo además la ficción de la unidad de acción de los partidos no catalanes.

Esa invisibilización del espacio de Unidos Podemos, sin embargo, no es frecuente, ya que los políticos de las confluencias sí suelen tener voz en las dos tertulias (y en Las Mañanas, de hecho, lideran en cuanto a número de intervenciones totales). La clave reside en las condiciones en las que esas intervenciones se producen. Además de los contraargumentos que reciben del moderador y los demás periodistas, que poseen una frecuencia varias veces mayor a los contraargumentos que reciben PSOE, PP y Ciudadanos, los entrevistados de Unidos Podemos deben someterse a otras continuas sutilezas en su contra.

Por ejemplo, el 6 de noviembre, el presentador dice en Las Mañanas que el ex-líder de Podem en Catalunya, Albano Dante, ha roto el carnet de Podem delante de las cámaras, algo falso o que al menos no ha sido mostrado en el programa ni reconocido por el protagonista ni ningún asistente al acto. Al día siguiente, se ponen las palabras "golpe de Estado" en boca de Dante como crítica a su ex partido cuando él sólo ha hablado de "intervención”. Pero el moderador no tiene suficiente y va más allá, construyendo una cuestión a partir de la propia expresión cuyo autor no es más que él mismo. Así, en referencia a Dante, critica que la expresión "golpe de estado" está siendo muy frecuentemente utilizada, juzguen ustedes si demasiado o no. Esto ocurre además pocos minutos después de que el periodista de Público José María Crespo haya tenido que corregir al moderador por conceder a la carta del preso Jordi Sánchez un contenido inexistente.

El 13 de noviembre, a lo largo del programa se da en cuatro ocasiones un dato erróneo: que el partido de Ada Colau posee 11 de los 45 concejales del Ayuntamiento de Barcelona (cuando en realidad son 41). Curiosamente, el dato refuerza el mensaje del moderador contra la decisión de las bases de Barcelona en Comú y no es rectificado, a pesar de que entre el primer error y el cuarto transcurre tiempo de sobra. Además, se insiste en el dato erróneo incluso delante del gráfico realizado ad hoc. Y no solo el moderador incurre en el error (en 3 ocasiones) sino también el reportero. La posición del presentador, que vertebra su entrevista a la protagonista y que es corroborada por el dato ficticio, es que el Ayuntamiento de Barcelona va a tener una inestabilidad enorme, ignorando que desde el principio de la legislatura la alcaldesa había gobernado en minoría.

\subsection{Todo vale contra las opciones independentistas}

Para ilustrar en los dos programas analizados el nivel de tolerancia a posiciones diversas, basta con enumerar algunas expresiones sobre los partidos soberanistas catalanes.

A) El independentismo está celebrando su muerte [la del fiscal Maza], Javier Ruiz, 20 de noviembre.

Para demostrar tal aseveración, a Las Mañanas de Cuatro le basta con mostrar varias veces las 
reacciones de un tuitero (al parecer ex-militante de ERC) mofándose de la muerte del fiscal Maza.

B) 7 de noviembre, Las Mañanas de Cuatro, 13:51 horas: "El independentimo en campaña" es el titular que acompaña a las imágenes de veinticinco contenedores y coches quemados en Sabadell, causando cortes de agua y luz.

C) Los primeros 15 minutos del programa del 14 de noviembre de Las Mañanas de Cuatro son suficientes para obtener 3 indicios sobre el tipo de tratamiento que reciben los partidos soberanistas.

- Rótulo inicial: Junts per Catalunya: El PdeCAT blanquea su marca con una lista encabezada por Puigdemont

- El PdeCat esconde, se desdibuja

- Puigdemont liquida a los del Pdecat, designa la lista

D) Al Rojo Vivo, 15 de noviembre: García Ferreras habla de "gatillazo", independentistas "en plena hiperventilación" o "Pamela Anderson y Assange", mofándose varias veces del apoyo internacional al Procés.

E) En el programa del 13 de noviembre, Javier Ruiz se pasa el programa repitiendo la expresión "marcha atrás" en referencia a los políticos independentistas. Pero lo más sorprendente es que el corte de video que introduce seis veces -de una entrevista a Puigdemont en Bélgica- no contiene ninguna de las palabras que él remarca "literalmente". Como hace frecuentemente, el moderador trata de forzar los hechos y adecuarlos a su titular. La realidad, sin embargo, es que en ninguno de los seis videos mostrados Puigdemont dice las palabras que Ruiz pone en su boca como literales. Además, el President ni siquiera aparece hablando propiamente sobre el tema en cuestión. En la sexta ocasión sí se muestra al menos el titular del periódico de la entrevista, Le Soir.

Pero los videos incoherentes con la presentación que se hace de ellos no terminan ahí. En el mismo programa, Javier Ruiz introduce un corte de Anna Gabriel -CUP- en el que ésta hace una alusión implícita a los comunes, criticando que alguien pueda estar equidistante en ese contexto político. Sin embargo, el presentador trata en todo momento el video como si Anna Gabriel estuviera hablando de "indepes de primera e indepes de segunda". Después de reintroducir el video del mismo modo, propone esas palabras manipuladas en la mesa de debate e incluso plantea la primera pregunta al siguiente invitado en esos términos, adjudicando a la CUP el haberse autoerigido como "únicos independentistas reales".

Y no hay que acudir a otra emisión para señalar un nuevo ejemplo de adulteración de las palabras de un protagonista. Ese día Juan Carlos Monedero, fundador de Podemos, ha comparecido en el Senado. Tal cosa es anunciada varias veces por Javier Ruiz a lo largo del programa y siempre lo hace enfatizando una supuesta denuncia de Monedero contra un "tribunal franquista". Sin embargo, cuando al fin nos presentan un corte de sus declaraciones, Monedero no dice en ningún momento la palabra "franquista", que durante toda la mañana había sido el titular del presentador. 


\section{5 "Más periodismo": estilo y autorreferencias}

El periodismo orientado al comentario, otra faceta del modelo mediterráneo o de pluralismo polarizado, está más presente en el modelo que representa García Ferreras. Javier Ruiz también realiza valoraciones en ocasiones, pero no tan a menudo como García Ferreras. Eso no implica, por supuesto, que el presentador de Las Mañanas de Cuatro -y el programa como tal- no dé su opinión sobre los distintos temas. De manera más implícita o explícita, su posicionamiento suele traslucirse, ya sea con el vocabulario empleado, el tono, el contenido de los reportajes, la insistencia para remarcar una determinada línea, etc.

En especial en Al Rojo Vivo, asistimos a una predominancia de preguntas irrelevantes del tipo “¿te sorprende?”, “¿te ha sorprendido?”... En el programa del 15 de noviembre, por ejemplo, García Ferreras utiliza esta intrascendente pregunta en al menos seis situaciones distintas. También son frecuentes para este periodista los planteamientos simplistas en los que se exige al entrevistado un sí o un no a cuestiones complejas. Este recurso, obviamente, incide en la simplificación del debate político.

Ni en Al Rojo Vivo ni en Las Mañanas de Cuatro hay espacio para la autocrítica. Las autorreferencias suelen ser para destacar la imparcialidad del programa y cómo no se deja influir por las múltiples presiones que recibe. El 16 de noviembre observamos la mejor definición de la clase de autocrítica que se da en estos programas. En al menos 13 ocasiones, Javier Ruiz se congratula por haber adelantado en 48 horas la noticia de que Jordi Sánchez sería el número 2 de la lista de Junts per Catalunya, a lo que hay que añadir una enhorabuena más de un colaborador. En otras cinco ocasiones, al menos, se dice que la estelada tapa la corrupción (aunque no esté hablando de la corrupción en Catalunya sino en toda España), lo que le sirve para una vez más sacar pecho y afirmar que en pocos sitios, en ninguno, podrán ver lo que están viendo [aquí] sobre Lezo.

El 8 de noviembre, se vanagloria de que según él la distancia [ideológica] en la mesa es sideral. Sin embargo, ante el tema central del día (la huelga en Catalunya), ninguno de los 6 integrantes de la mesa representa una posición a favor de la misma. El conductor del programa tiene como leitmotiv que se trata de una huelga política y que las huelgas políticas no son legales. A él se suman los periodistas Cristina de la Hoz, Ana Terradillos, que llama "barbaridad" a la jornada de huelga, o Jose María Calleja, que habla continuamente de violencia. Solo dos tertulianos no condenan rotundamente la huelga: Pere Mas, que afirma poseer sentimientos encontrados, y Ernesto Ekaiser, que opina poco sobre el tema y mantiene un perfil moderado.

En los 50 programas que componen la muestra, la práctica diaria de los conductores de Las Mañanas de Cuatro y Al Rojo Vivo corrobora completamente lo concluido por Hallin y Mancini:

"La distancia entre lo ideal y la realidad es mucho mayor en países como Italia o España, donde los periodistas se declaran fieles seguidores del modelo liberal de neutralidad y objetividad, a pesar de que la práctica real del periodismo esté profundamente arraigada a una tradición de prensa de opinión partidista" [citado en Busquet 2010: 168].

\section{Conclusiones}

Los resultados de la doble aproximación cuantitativa y cualitativa a las dos tertulias políticas 
de referencia corroboran, por un lado, la ubicación de España como un sistema mediático altamente vinculado a la política y a partidos políticos concretos y, por el otro, la estrechez de un pluralismo que trata muy desigualmente a las distintas opciones políticas y no alcanza a dar cabida al cuestionamiento del sistema económico ni político, que trata con rechazo las referencias a la democratización, a la calle, a las redes sociales o al cambio profundo, mientras idolatra las señales macroeconómicas o de los mercados. En el periodo estudiado, las dos tertulias han ofrecido un ubicuo encuadre negativo del Procés soberanista en Catalunya, tomando partido en todo momento (también en los análisis económicos, utilizados como refuerzo de los argumentos en la misma dirección).

Coherentemente, las entrevistas a políticos soberanistas catalanes presentaron un índice espectacularmente mayor de contraargumentos y refutaciones de los periodistas, lo que dio lugar a un menor número de intervenciones por cada contraargumento recibido: los partidos soberanistas catalanes fueron refutados cada 1,50 intervenciones en Las Mañanas de Cuatro (por 8,34 de PP, PSOE y C`s) y cada 2,23 en Al Rojo Vivo (contra los 12,62 de los partidos “unionistas").

La primera hipótesis es validada en cuanto a que el número de intervenciones de los distintos partidos se adecúa proporcionalmente a la representación parlamentaria de cada uno: 298 intervenciones totales para el PSOE, 254 para Unidos Podemos y 119 para Ciudadanos (85, 67 y 32 escaños en el Congreso, respectivamente). Se dan dos justificadas excepciones: 1) los partidos catalanes cuentan con un número de intervenciones muy superior al que les correspondería por número de escaños debido a que en el periodo examinado ambas tertulias conceden a la "cuestión catalana" una prioridad absoluta; 2) el menor peso del PP puede deberse a un menor interés de este partido por exponerse mediáticamente, al menos en tertulias que se ubican aparentemente lejos de su zona ideológica de confort.

El elemento parlamentario del periodismo mediterráneo queda también probado en tanto no es entrevistada ninguna formación extra-parlamentaria.

Es igualmente contundente el resultado del otro punto de la primera hipótesis, pues las diferencias en el tratamiento a los partidos son abrumadoras. Es obvio que estas divergencias tienen un origen ideológico porque las dos tertulias coinciden en la esencia de los resultados tan dispares que conceden a los partidos: Ciudadanos y sobre todo el PSOE en cabeza con un margen amplísimo y los partidos soberanistas en los últimos puestos, muy alejados.

La única disconformidad relevante entre los dos programas se da precisamente respecto a PP y UP: Las Mañanas de Cuatro ofrece a los representantes de Unidos Podemos un tratamiento bastante peor del que otorga al PP, mientras que Al Rojo Vivo refuta menos en proporción a los representantes de UP que a los del PP. Esto iría en la línea que establecían la segunda y tercera hipótesis, en cuanto La Sexta es ubicada claramente más a la izquierda que Cuatro. Sin embargo, lo que es cierto en términos relativos en la comparación Al Rojo Vivo-Las Mañanas de Cuatro no lo es respecto a los datos generales de ambas tertulias: el partido de gobierno, identificado como el más a la derecha en el CIS, efectúa 4,40 intervenciones por cada argumento contrario en el global, mientras que la coalición ubicada más a la izquierda, Unidos Podemos, efectúa menos: 3,19 intervenciones por contraargumento recibido.

La segunda hipótesis es descartada: hay 4 partidos en Las Mañanas de Cuatro y 3 partidos 
en Al Rojo Vivo que obtienen peor tratamiento que el PP. Los datos de Al Rojo Vivo por separado tampoco son suficientes para dar por buena la tercera hipótesis (un menor ratio de contraargumentos para la izquierda), pues la ligera ventaja de UP sobre PP se ve más que compensada por el contundente framing negativo a ERC y CUP y por el trato privilegiado que recibe Ciudadanos respecto a Unidos Podemos (15 argumentos por refutación para C`s contra los 6,48 permitidos a UP).

En el total de las dos tertulias, el PSOE lidera en las dos principales estadísticas registradas: es el partido que más interviene y el que recibe menos contraargumentos de promedio. Además, en Al Rojo Vivo se han registrado 4 alabanzas expresas a los entrevistados del PSOE. Por tanto, las 205 intervenciones del PSOE han recibido más alabanzas (4) que contraargumentos (3) en Al Rojo Vivo. Un dato incompatible con cualquier noción de control del poder. Para hacernos una idea precisa del alcance del agravio comparativo, la suma de ERC, PdeCAT y CUP, aun disponiendo de 2 intervenciones menos que el PSOE en Al Rojo Vivo, recibieron en total 75 contraargumentos (el PSOE, 3).

Unidos Podemos lidera en Las Mañanas de Cuatro en número de intervenciones, aunque los entrevistados de esta coalición recibieron en el período estudiado un total de 45 contraargumentos de los periodistas de Las Mañanas de Cuatro, mientras que el PP recibió 6, el PSOE 4 y Ciudadanos 3.

Además de las semejanzas ideológicas, las tertulias estudiadas presentan similitudes en cuanto al formato, en coherencia con los resultados de Pastor Francisco (2015), que también tomó un programa de La Sexta y otro de Cuatro de contenido político (La Sexta Noche y Un Tiempo Nuevo).

Los resultados demuestran que la instalada noción de La Sexta como "izquierda" y Cuatro como "centro izquierda" es incorrecta: al menos en lo relativo a estas dos paradigmáticas tertulias, ambas cadenas no están vinculadas a la izquierda (UP dispone de 3,19 intervenciones por contraargumento en la media total y ERC y CUP menos de 2) sino más propiamente a los partidos pro-artículo 155 (10,89 intervenciones) y sobre todo al PSOE (23,84 intervenciones por contraargumento). Que PSOE y Compromís sean los mejor tratados en Las Mañanas podría ser un argumento para justificar su etiqueta de centro-izquierda, de no ser porque PP y C's disfrutan un enfoque muchísimo más positivo que el de UP, ERC y CUP.

Respecto a lo anterior, otra derivada de los frutos de la investigación es la confirmación de una deficiencia fundamental en el sistema mediático español. Si a la población a la izquierda del PSOE (que supera el 20\% del voto, según las dos últimas elecciones generales) sumamos la población que no tiene la nación española como principal referencia nacional, podemos decir a grandes rasgos que un tercio de los ciudadanos españoles no posee ningún gran medio de comunicación estatal que les represente, ni público ni privado, pues se une el hecho de que entre los diarios escritos existe un pluralismo aún menor que en televisión. Debido a la centralidad que siempre se ha otorgado a los medios de comunicación en la configuración de sistemas democráticos dignos de tal nombre, esta deficiencia es de gran gravedad.

Como advierten Fenoll y Rodríguez Ballesteros (2016), la ubicación de los grandes grupos de comunicación en torno a los dos principales partidos de las últimas décadas conllevó un escaso pluralismo interno y el silenciamiento de la información sobre las fuerzas políticas 
ajenas al sistema bipartidista. Los resultados del presente trabajo apuntalan esa tendencia mientras señalan el desenvolvimiento de una nueva fase, en la que la entrada de nuevos actores políticos se resuelve con la plena integración y aceptación de Ciudadanos en el sistema mediático a la vez que un enfoque negativo para los que cuestionan la distribución de poder atada en 1975-1978 (en estos programas, Unidos Podemos y las formaciones soberanistas catalanas).

\section{Bibliografía}

La presente investigación ha sido financiada por el Ministerio de Educación a través de las ayudas FPU (Formación de Profesorado Universitario)

Abril, G. (2010). "Cultura visual y espacio público-político”. CIC Cuadernos de Información y Comunicación, vol. 15, pp. 21-36.

http://revistas.ucm.es/index.php/CIYC/article/viewFile/CIYC1010110021A/7198

Botella, J. (2006). "El pluralismo en el audiovisual: problemática y futuro". Quaderns del CAC, núm. 26.

https://www.cac.cat/pfw files/cma/recerca/quaderns cac/Q26ES Botella.pdf

Busquet, J (2010). [Crítica del libro Sistemas mediáticos comparados. Tres modelos de relación entre los medios de comunicación y la politica, de Daniel C. Hallin y Paolo Mancini].

Revista Española de Investigaciones Sociológicas (Reis), núm. 129, pp. 165-188.

http://www.reis.cis.es/REIS/PDF/REIS 129 071262609522690.pdf

Campos Domínguez, E.; López García, G. y Valera Ordaz, L. (2013). “¿Reproduciendo la lógica mediática? Un estudio empírico sobre el impacto del debate electoral español en nuevos y viejos medios".

http://mediaflows.es/wp-content/uploads/2014/12/Valera-Campos-y-LopezGarcia-2013.pdf

Carniel Bugs, R. y Sabés Turmo, F. (2014). "La observancia del pluralismo político en el audiovisual mediterráneo: autoridades independientes y criterios de regulación de la televisión”. Historia y Comunicación Social, vol. 19, número especial Febrero, pp. 273-286.

https://ddd.uab.cat/pub/artpub/2013/175770/45027-71031-2-PB.pdf

Centro de Investigaciones Sociológicas (2016). Estudio número 3145. Postelectoral de las Elecciones generales, julio 2016 .

http://www.cis.es/cis/export/sites/default/-Archivos/Marginales/3140 3159/3145/es3145mar. pdf

Cotarelo, R. y Gil, J. (comp.) (2017). Ciberpolitica. Hacia la cosmópolis de la información y la comunicación. Madrid: Instituto Nacional de Administración Pública.

Fenoll, V. y Rodríguez-Ballesteros, P. (2016). "Repercusión de los resultados electorales europeos de 2014 en la cobertura mediática de Podemos”. Comunicació. Revista de recerca i d'anàlisi, no33, vol. 2, pp. 65-85.

http://revistes.iec.cat/index.php/TC/article/view/142257/141166

GYPEyOP/Mediaflows (2017). Encuesta sobre medios y comunicadores. Universitat de València. https://www.uv.es/pavia/Informe Encuesta Medios.pdf 
Hallin, D. C. y Mancini, P. (2004). Sistemas mediáticos comparados. Tres modelos de relación entre los medios de comunicación y la politica. Cambridge: Cambridge University Press.

M.L. Humanes, M.D. Montero Sánchez, R. Molina de Dios, A. López-Berini (2013). "Pluralismo y paralelismo político en la información televisiva en España”. Revista Latina de Comunicación Social, 68. http://www.revistalatinacs.org/068/paper/990 Fuenlabrada/24 Humanes.html

León Gross, T. y Gómez Calderón, B. J. (2011). "La tertulia en España: medios públicos, la última frontera de la pluralidad”. Estudios sobre el mensaje periodístico, vol. 17, núm. 1, pp. 67-80. Madrid: Servicio de Publicaciones de la Universidad Complutense.

http://revistas.ucm.es/index.php/ESMP/article/view/36946/35755

López García, G. (2004). Comunicación electoral y formación de la opinión pública. Las elecciones generales de 2000 en la prensa española (Tesis doctoral). Valencia: Servei de Publicacions de la Universitat de València.

López García, G. y Valera Ordaz, L. (eds.) (2017). Pantallas electorales. El discurso de partidos, medios y ciudadanos en la campaña de 2015. Barcelona: Editorial UOC.

Miguel de Bustos, J. C. (2004): "Sobre pluralismo y diversidad". ZER - Revista de Estudios de Comunicación, vol. 9, no 16, pp. 9-16. Bilbao: Servicio de Publicaciones de la Universidad del País Vasco.

http://www.ehu.eus/ojs/index.php/Zer/article/view/5301/5157

Palao Errando, J. A. y García Catalán, S. (2011). “¿Política-basura? Modelos de representación en la telebasura y la tertulia política". Murcia, X Congreso AECPA.

http://www.aecpa.es/uploads/files/modules/congress/10/papers/137.pdf

Pastor Francisco, T. (2015). Las tertulias politicas en televisión. Una comparativa entre el modelo de "Un Tiempo Nuevo" y el de "La Sexta Noche". Trabajo Fin de Grado, curso 2014/2015, Universitat Jaume I.

http://repositori.uji.es/xmlui/bitstream/handle/10234/145245/TFG 2014 pastorT. pdf? sequence $=1$

Rodríguez Pardo, J. (2005). "Concentraciones mediáticas en España y pluralismo informativo: una búsqueda de los criterios iusinformativos de control de la Comisión Europea (1990-2004)". Sphera Pública, núm. 5, pp. 109-132. Murcia: Universidad Católica San Antonio de Murcia. http://www.redalyc.org/pdf/297/29700508.pdf

Sánchez Castillo, S.; Peris Blanes, Á. y Fenoll, V. (2016). "Europeísmo y euroescepticismo en los medios digitales españoles. Diferencias de encuadre en la cobertura de las elecciones europeas de 2014". Trípodos, no 39, pp. 205-221.

http://www.tripodos.com/index.php/Facultat Comunicacio Blanquerna/article/view/389/442

Santamaría Guinot, L. (2017). "Identidad emocional y tertulias televisivas en el contexto político de Catalunya”. ZER - Revista de Estudios de Comunicación, vol. 22, núm. 43, pp. 129-147.

http://www.ehu.eus/ojs/index.php/Zer/article/view/17720/16843

Wirth, W., y Schramm H. (2005). "Media and Emotions". Communication Research Trends, volume, 24(3), pp. 1-39. Recuperado de http://cscc.scu.edu/trends/v24/v24 3.pdf. 
MHCJ nº 10 (1) | Año 2019 - Artículo no 2 (137) - Páginas 39 a 56 - mhjournal.org

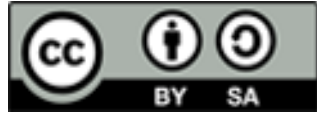

Licencia Creative Commons

Miguel Hernández Communication Journal

mhjournal.org

\section{Cómo citar este texto:}

Noel Bandera López (2019): Pluralismo político y rol del moderador en tertulias televisivas: Al Rojo Vivo y Las Mañanas de Cuatro, en Miguel Hernández Communication Journal, n¹0 (1), pp. 39 a 56. Universidad Miguel Hernández, UMH (Elche-Alicante). DOI: http://dx.doi.org/10.21134/mhcj.v10i0.265 